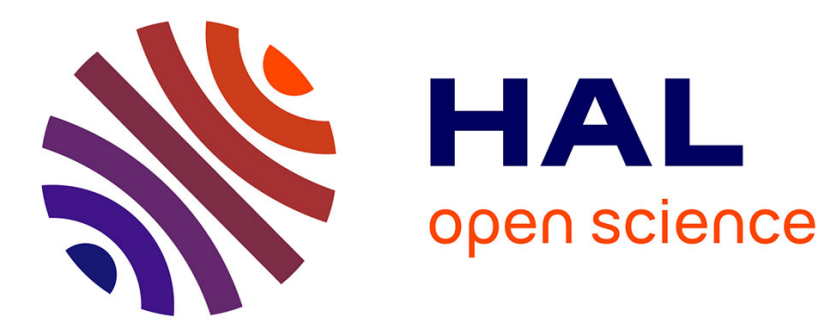

\title{
Exclusive contracts and demand foreclosure
}

David Spector

\section{To cite this version:}

David Spector. Exclusive contracts and demand foreclosure. 2007. halshs-00588311

\section{HAL Id: halshs-00588311 \\ https://shs.hal.science/halshs-00588311}

Preprint submitted on 22 Apr 2011

HAL is a multi-disciplinary open access archive for the deposit and dissemination of scientific research documents, whether they are published or not. The documents may come from teaching and research institutions in France or abroad, or from public or private research centers.
L'archive ouverte pluridisciplinaire HAL, est destinée au dépôt et à la diffusion de documents scientifiques de niveau recherche, publiés ou non, émanant des établissements d'enseignement et de recherche français ou étrangers, des laboratoires publics ou privés. 


\section{PARLS SCHOOL OF ECONOMICS}

WORKING PAPER Nº 2007 - 07

Exclusive contracts and demand foreclosure

David Spector

JEL Codes: L12, L13, L14, L41, L42

Keywords: exclusive dealing, foreclosure, exclusionary strategies

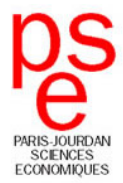




\title{
Exclusive Contracts and Demand Foreclosure*
}

\author{
David Spector $^{\dagger}$
}

March, 2007

\begin{abstract}
A firm may decide to have some of its customers sign exclusive contracts in order to deprive a rival of the minimum viable size, exclude it from the market, and enjoy increased market power. If contracts are required to be simple enough, this strategy may induce inefficient exclusion even if the excluded firm is present at the contracting stage. Exclusive contracts may thus cause inefficient eviction, not only entry-deterrence, even though the former is less likely than the latter. However, complex enough contracts, if feasible, would allow agents to reach a Pareto-optimum, without inefficient exclusion.
\end{abstract}

${ }^{*}$ I am grateful to Severin Borenstein, Bernard Caillaud, Jeff Ely, Joseph Farrell, Bruno Jullien, Zvika Neeman, Debraj Ray, Patrick Rey, Daniel Rubinfeld, Jean Tirole and Thibaud Vergé for their comments on an earlier draft.

${ }^{\dagger}$ PSE (Paris School of Economics/Paris Sciences Economiques, UMR 8545 CNRSEHESS-ENPC-ENS). Address: Paris School of Economics, 48, boulevard Jourdan, 75014 Paris; France (email: spector@pse.ens.fr). 


\section{Introduction}

This paper aims to clarify the circumstances under which a firm may sign exclusive contracts with some of its customers in order to exclude a rival, even though exclusion reduces social welfare. This clarification is important both for its own sake and from the viewpoint of antitrust policy. Indeed, the legal treatment of exclusive dealing appears to be responsive to the twists and turns of economic theory. For example, the so-called Chicago critique, which purported to prove that the reasonings underpinning the traditional hostility toward exclusive dealing were flawed, seems to have induced U.S. Courts to progressively soften their handling of exclusivity clauses. ${ }^{1}$

From a theoretical viewpoint, the need for clarification stems from the fact that, while the recent body of literature rigorously described several scenarios of welfare-reducing exclusion through the use of exclusive contracts, it still leaves readers wondering which conditions exactly are necessary for these anticompetitive outcomes to occur in equilibrium. The main contribution of this paper is to show that, although the existing theories of socially harmful foreclosure through exclusive contracts assume that some of the adversely affected parties are not present during the contracting stage, this assumption is unnecessary. Such an outcome can also occur when all affected parties are present, as long as contracts are required to be simple enough. This theoretical result is relevant for antitrust policy, because most of the relevant case

\footnotetext{
${ }^{1}$ See Wiley (1998) and Gilbert (2000) for a survey of the legal treatment of exclusive contracts and an economic discussion.
} 
law involves situations in which the allegedly excluded firms were initially in the market and thus perfectly able to respond to the disputed contracts with counteroffers of their own.

\subsection{Relation to the literature}

The first analysis of exclusive contracts emanated from the "Chicago school" and dismissed the view that these contracts could be used by a firm in order to exclude a rival and increase its market power. The Chicago school argument is simply that if such exclusion is socially inefficient, the payment which the excluding firm has to grant consumers in order to "bribe" them into agreeing to exclusivity would exceed the incumbent firm's gain from deterring entry or inducing exit ${ }^{2}$ Exclusive dealing must them have other, probably procompetitive motives. $^{3}$

The "post-Chicago" literature has identified several circumstances under which socially harmful exclusive contracts may arise.

Matthewson and Winter (1987), for example, showed that a manufacturer may profitably use impose exclusivity to a local retailer in order to foreclose a rival in a local market, and that this outcome may be (but need not be) socially harmful. ${ }^{4}$ But this result breaks down if nonlinear pricing is feasible ${ }^{5}$.

\footnotetext{
${ }^{2}$ See Posner, (1976, p. 212) and Bork (1978, p. 309). For a generalized and rigorous version of the Chicago critique, see Bernheim and Whinston (1998, hereinafter "BW"), especially Section III; and O'Brien and Shaffer (1997).

${ }^{3}$ See, e.g., Marvel (1982) and Segal and Whinson (2000b).

${ }^{4}$ See also Comanor and Frech (1985) for a related analysis.

${ }^{5}$ See the discussion in BW and O'Brien and Shaffer (1997). However, Spector (2007) shows that Mathewson and Winter's (1987) result may still hold under nonlinear pricing
} 
On the other hand, various papers have shown that exclusivity clauses may facilitate profitable entry deterrence or competitors' eviction. Their common theme is that inefficient exclusion may occur when some adversely affected parties (a potential entrant, or future consumers) are absent at the contracting stage, and thus cannot make the payments to other parties which are necessary for Coasian bargaining to take place and lead to efficiency.

The seminal paper in this branch of the literature is Rasmusen et al. (1991, henceforth, RRW), complemented by Segal and Whinston (2000a, henceforth SW) - these papers are the ones most closely related to ours. They show that, if increasing returns make a minimum scale of operation necessary for profitable entry, an incumbent can achieve full exclusion cheaply by exploiting the lack of buyers' coordination, or by discriminating between buyers. The idea is that even if buyers as a whole lose when entry is deterred, entry deterrence can be profitable because the excluding firm does not need to bribe all its potential customers into signing an exclusivity agreement. It only needs to have some of them sign exclusive contracts, just enough to deprive the potential entrant from the minimum viable scale. The incumbent can then fully exploit its market power vis-à-vis all the potential customers, including those who did not sign an exclusive contract and whose consent was not bought. The entrant's need for a minimum scale of operation thus generates a contracting externality across customers which the incumbent

if the seller does not know each customer's demand function. This is simply a consequence of the more general fact that nonlinear pricing together with asymmetric information resembles linear pricing. 
can exploit ${ }^{6}$. In this case, the Chicago critique breaks down because the excluding firm does not need to compensate the loss suffered by all buyers, but only that suffered by some of them. A coordination failure among buyers may lead to the same result. ${ }^{7}$ Variants of RRW consider the possibility of buyers forming coalitions ${ }^{8}$ or the impact of competition among buyers ${ }^{9}$. But all of them stick to the assumption that the potential entrant does not take part to the contracting game.

A related idea can be found in models assuming that some adversely affected parties, other than the excluded firm, cannot take part in the contracting game. These parties can be consumers in a future market ${ }^{10}$, or agents whom transaction costs deter from participating to the contracting game ${ }^{11}$. In yet one more category of papers, socially harmful exclusion may result from contracts signed between wholesalers and retailers because final consumers are left aside ${ }^{12}$.

All these models assume that some adversely affected parties are absent from the contracting game. This raises two issues. The first one is theoret-

\footnotetext{
${ }^{6}$ For a systematic treatment of contracting with externalities, see Segal $(1999,2003)$ and Segal and Whinston (2003).

${ }^{7} \mathrm{SW}$ stresses that the equilibria in which exclusion is achieved by exploiting the lack of coordination among buyers are not perfectly coalition-proof.

${ }^{8}$ Innes and Sexton (1994).

${ }^{9}$ Motta and Fumagalli (2006), and Simpson and Wickelgren (2004, 2005).

${ }^{10} \mathrm{BW}$, section IV

${ }^{11}$ Gans and King (2002).

${ }^{12}$ Hart and Tirole (1990); Lin (1990); O'Brien and Shaffer, (1993). Simpson and Wickelgren (2004) belongs to this set of papers (since the presence of downstream consumers exacerbates the inefficiency) while at the same time being a variant of RRW (since the excluded firm in their model is a potential entrant unable to participate to the contracting game).
} 
ical. In most of the aforementioned models, contracts are restricted to take a rather simple form. For example, RRW and SW only consider simple exclusive contracts, ruling out both breach penalty provisions and conditional contracts. ${ }^{13}$ A natural question emerges then: is the possibility of socially harmful eviction driven by the absence of some adversely affected parties during the contracting game, or by the restrictions imposed on the nature of feasible contracts? Clearly, if these two assumptions were lifted, i.e., if all affected parties could enter into very complex contracts, unhindered Coasian bargaining would induce an efficient outcome. But what is the respective importance of each of these two assumptions?

This question brings us to the second issue. The aforementioned literature is at odds with the facts of much of the relevant case law, which deals with settings where the excluded firm(s), or other potentially harmed parties, could in principle have responded to the alleged exclusionary strategy. This point has been made by Whinston (2001, pp. 68-69) in his discussion of the US v Microsoft case, and by Rasmusen et al. (2004), who noticed that their theory failed to apply to the landmark Lorain Journal case, because the alleged victim was already present in the market when the disputed exclusivity clauses were offered. The same remark applies to several recent

\footnotetext{
${ }^{13}$ Aghion and Bolton (1987) is an exception. They show that inefficient exclusion may occur if the incumbent can offer exclusive contract together with a breach penalty provision. But this result is driven by uncertainty about the potential entrant's costs, which causes the incumbent to exclude a more efficient entrant "by mistake", as a result of poorly calculated breach penalties. Also, a section of SW considers breach penalties, but under very specific assumptions.
} 
nonlinear pricing cases in which the disputed schemes were close to exclusivity requirements, like the European Michelin II case. ${ }^{14}$

\subsection{This paper's contribution}

This paper attempts to precisely identify the factors which may cause inefficient exclusion to occur, and in particular to disentangle between two possible factors, namely limits on the nature of contracts and limits on which agents may offer contracts. Section 2 presents a very general, reduced-form model, of which RRW, SW, and BW are subcases. It is first applied to the familiar incumbent-entrant case (Section 3), with the following results.

- Inefficient entry deterrence may occur even when discriminatory offers are prohibited, even without any coordination failure among buyers. A necessary condition for this is that firms' profits in a no-exclusion equilibrium be strictly positive (Proposition 1).

- Inefficient entry deterrence is even more likely to occur when discriminatory offers are possible. This is proved in Proposition 2, of which the results in RRW and SW are special cases.

- The possibility to include breach penalty provisions in exclusive contracts decreases the likelihood of inefficient entry deterrence, but does not eliminate it (Proposition 3).

\footnotetext{
${ }^{14}$ European Commission Decision 2002/405/EC, Michelin, 2002 O.J. (L 143).
} 
- The combination of breach penalty provisions and conditional offers is enough to make inefficient entry deterrence impossible (Proposition 4).

The paper then considers the two-incumbent case, in which the potential excluder and the potentially excluded firm are on an equal footing as regards the possibility of making offers (Section 4). The results are as follows.

- There always exists a perfect coalition-proof equilibrium without exclusion, and there exists no equilibrium with exclusion if discrimination is prohibited (Proposition 5), or if exclusive contracts can include breach penalty provisions (Proposition 7).

- A perfect coalition-proof equilibrium with inefficient eviction may exist alongside a no-exclusion one if simple, discriminatory exclusive contracts can be offered, without breach penalty provisions. But the existence of an exclusionary equilibrium is in general less likely than in the entrant-incumbent case (Proposition 6). We view this result as the most important one of this paper, because it means that exclusive contracts can induce inefficient eviction and not only entry deterrence. Even more strikingly, one of the implications of Proposition 6 is that under the special assumptions of RRW and SW, exclusion is as likely to occur in the two-incumbent case as in the incumbent-entrant case.

These results are summarized in Table 2, in Section 5 . 


\section{The model}

The assumptions of the model are kept as simple as possible for the sake of tractability. There are two firms, labeled Firm 1 and Firm 2, and two consumers $(a$ and $b)$. Firms' cost structures are different, while consumers have identical preferences. ${ }^{15}$

In order to conduct the analysis at a general enough level, we specify reduced forms rather than detailed preferences and technologies. More specifically, we assume that the institutional context is as follows.

During the first phase (which may be subdivided into different periods), consumers and firms can enter into contracts, which may involve lump-sum transfers, a commitment by a firm to serve a consumer, possibly an exclusivity requirement, as well as, possibly, other characteristics. Which firms can offer contracts (depending on whether the situation considered is an incumbententrant one, or a two-incumbent one), which type of contract can be offered, whether discrimination is allowed, the timing of moves, is described in greater detail below. Different assumptions correspond to different "contractual environments", which this paper compares. At the end of this first period, some lump-sum transfers have been made, some firms are committed to deal with some consumers, and some consumers are committed not to deal with some firms.

\footnotetext{
${ }^{15}$ The assumption that consumers have identical preferences is made in RRW as well. RRW also assumes that firms are identical (except for the fact that one is incumbent), but SW relaxes this assumption when discussing breach penalties (in Section IV).
} 
During the second phase, subject to the constraints induced by the contracts which have been signed (i.e. an obligation to deal or a prohibition from dealing), firms and consumers deal with each other, which results into payoffs for the various parties. How these payoffs are determined is not the point of this paper. They may result from bargaining, or from firms, or consumers, making take-it-or-leave-it offers, involving linear or nonlinear pricing, etc. For our purposes, there is no need to enter into these details, because the only relevant variables are, for each possible situation, the profit accruing to each firm, and each consumer's surplus.

Finally, the list of firm-consumer deals actually consummated (as per second phase decisions, themselves constrained by first phase outcomes) and the first phase lump-sum transfers together determine each firm's profit and each consumer's surplus level.

\subsection{Consumer preferences}

Consumers are assumed to have identical preferences, given by Table 1 below. ${ }^{16}$

\section{Table 1: consumer preferences}

\footnotetext{
${ }^{16}$ The magnitudes $V$ and $U_{i}$ in Table 1 are indirect utility levels. They are equal to the utility levels achieved by a consumer dealing with either firm (or with both), given the nature of the strategic interaction between firms and consumers, left outside of the model.
} 


\begin{tabular}{|l|l|}
\hline Situation & Consumer's utility \\
\hline A consumer is served by both firms & $V$ \\
\hline A consumer is served by Firm $i$ only & $U_{i}$ \\
\hline
\end{tabular}

\subsection{Firm profits}

Firm 1's profit is equal to $\lambda \pi_{1}+\mu \varpi_{1}$ where $\lambda$ and $\mu$ are, respectively, the number of consumers served by both firms and the number of consumers served by Firm 1 only. It is assumed that $\boldsymbol{b}_{1}>\pi_{1}$ in order to capture the idea that Firm 1's profit is greater in monopoly than in duopoly. The assumption that Firm 1's per customer profit only depends on the degree of competition for that customer is consistent with the assumption that Firm 1's technology displays constant returns to scale.

Firm 2's technology is assumed to be characterized by economies of scale in the following sense. If Firm 2 serves both consumers, then its profit is equal to $\lambda \pi_{2}+\mu \varpi_{2}$ where $\lambda$ and $\mu$ are, respectively, the number of consumers served by both firms and the number of consumers served by Firm 2 only (with, obviously, $\lambda+\mu=2$, and $\wp_{2}>\pi_{2}$ ). However, if Firm 2 serves a single consumer, its profit is equal to $\boldsymbol{B}_{2}$ (if it is alone in serving that consumer) or $s_{2}$ (if that consumer is also served by Firm 1 ), with $b_{2}>s_{2}$ (in order to account for the fact that Firm 2's profit is greater under monopoly than under duopoly).

The following assumptions about parameters are made throughout the paper for $i=1$ and $i=2$ : 


$$
\begin{gathered}
\pi_{i} \geq 0 \\
V>U_{i} \\
V+\pi_{1}+\pi_{2}>U_{i}+\mathfrak{b}_{i} \\
s_{2}<\mathbf{b}_{2}<0
\end{gathered}
$$

These assumptions have the following interpretation. (1) implies that competition leads to nonnegative profits for both firms if each has unrestricted access to both consumers. (2) and (3) imply that consumer as well as aggregate welfare is greater under competition than under monopoly. Finally, (4) means that because of economies of scale, Firm 2 is better off serving no consumer at all than serving only one of them, even as a monopolistic supplier. This assumption is central to all our results: it implies that if Firm 1 succeeds in signing an exclusive contract with one consumer, then Firm 2 is better off not serving any of the two consumers, because serving only one of them would not allow it to recover its fixed costs. This assumption is indeed central to the results in RRW, SW, and BW.

All the assumptions above are satisfied in RRW. ${ }^{17}$, but our model is far

\footnotetext{
${ }^{17}$ The correspondence is as follows.In RRW, $\pi_{1}=\pi_{2}=0$ (since both firms' duopoly profits are zero), $V=C S(\bar{c}), U_{1}=U_{2}=C S\left(p^{m}\right)$, and $\wp_{1}=\emptyset_{2}=\left(p^{m}-\bar{c}\right) q\left(p^{m}\right)$. RRW's assumption stated as " $\pi<x^{*} "$ is equivalent to (3), since it means that aggregate welfare is greatest when both firms serve consumers. Finally, the assumption that the entrant
} 
more general. For example, it allows for the possibility that both firms sell differentiated goods as well as for nonlinear pricing.

\section{Foreclosing an entrant through exclusive contracts}

In this section, we deal with the situation analyzed in RRW and SW, i.e. that of an incumbent able to offer exclusive contracts. We start by assuming that the incumbent is only able to offer simple exclusive contracts (i.e. without any breach possibility), and we examine two alternative cases, depending on the incumbent's ability to discriminate across consumers. Our results in the case where discrimination is allowed coincide with those of SW. We then turn to more complex contracts.

\subsection{Simple exclusive contracts without discrimination}

In accordance with RRW and the related literature, we start by considering the following simple game.

makes losses when serving a single consumer is equivalent to the identity $N^{*}=1$ in RRW. There is however a difference between RRW and this paper. In RRW, both firms have identical costs, but the assumption that the incumbent would make losses if it served only a small number of customers is irrelevant because of its first-mover advantage. In this paper, because firms are on equal terms regarding the timing of offers, we need to depart from the assumption of identical costs for simplicity, in order to limit the number of equilibria. In this sense, firms are not on equal terms as regards costs. But the point of this paper is simply to investigate the consequences of them being in equal terms as regards contracts, not costs. 
Stage 1. Firm 1 may offer each consumer a contract specifying that (i) the consumer commits not to purchase from Firm 2; and (ii) a lump-sum transfer from Firm 1 to the consumer. Firm 1 cannot discriminate among consumers: a contract offered to one consumer must be available to the other one.

Stage 2. Consumers simultaneously decide whether to sign the contracts possibly offered to them in Stage 1. The lump-sum payments corresponding to the contracts which end up being signed are made.

Stage 3. Observing the outcome of Stage 2, Firm 2 decides which consumers it wants to serve. It cannot decide to serve a consumer who signed an exclusive contract in Stage 2. However a firm can serve a consumer with which it signed no contract at the previous stage. Each consumer's welfare level and each firm's profit is then determined according to Table 1, depending Firm 2's choices. Lump-sum payments provided in exclusive contracts signed in Stage 2 are subtracted from Firm 1's profit and added to the signing consumers' welfare level.

Equilibrium multiplicity is pervasive when exclusive contracts are possi$\mathrm{ble}^{18}$. Following the existing literature, and in order to rule out situations where exclusive contracts result only from of a lack of coordination between consumers or firms (a possibility arising for example in RRW), we restrict

\footnotetext{
${ }^{18}$ See, e.g., BW, SW, O’Brien and Shaffer, (1997).
} 
our attention to perfect coalition-proof Nash equilibria (PCPNE), as defined in Bernheim et al. (1987).

Proposition 1 In any PCPNE, inefficient entry deterrence occurs if and only if it maximizes the joint surplus of the incumbent and the two consumers, i.e. if $U_{1}+\wp_{1}>V+\pi_{1}$.

Notice that for exclusion to happen in Proposition 1, it must be the case that $\pi_{2}>0$. The reason is that, if $\pi_{2}=0$, Assumption (3) is equivalent to $U_{1}+\wp_{1}<V+\pi_{1}$. Consequently, under the assumptions of RRW and SW, exclusion cannot occur in a PCPNE is discrimination is prohibited.

\subsection{Simple exclusive contracts with discrimination}

We assume now that the incumbent can discriminate among consumers. In this case, exclusion is more likely because in order to exclude, the incumbent only needs to convince one consumer to sign an exclusive contract: if it does, the entrant will decide to serve no consumer at all rather than only one, and the incumbent will exert its market power vis-à-vis both consumers while only having to compensate one of them.

Proposition 2 In any PCPNE, inefficient entry deterrence occurs if and only if $U_{1}+2 \boldsymbol{b}_{1}>V+2 \pi_{1}$, i.e. if the joint surplus of Firm 1 and one consumer is greater under exclusion than under no-exclusion. 
Proposition 2 coincides with Proposition 3 in SW if the special assumptions of RRW are made. The proof of this result is straightforward. Coalitionproofness implies that for Firm 1 to induce a consumer to enter into an exclusive contract, it must guarantee this consumer a welfare level equal to at least $V$. Indeed, if in equilibrium both consumers earn less than $V$, they could form a coalition and jointly decide not to sign contracts. This would yield each consumer a welfare level of $V$ (because Firm 2's entry would not be deterred) and not signing would be an equilibrium (since signing an exclusive contract when the other consumer does not would cause the signing consumer's welfare level to fall below $V$ ). Therefore, Firm 1 can sign an exclusive contract only against a lump-sum transfer equal to at least $V-U_{1}$, which is the minimum amount needed to keep the signing consumer's welfare level equal to $V$ while deterring entry. Firm 1's maximum profit when offering such an exclusive contract is thus $2 \boldsymbol{b}_{1}+V-U_{i}$ (because, as a consequence of assumption (4), Firm 2 will decide not to enter if it observes that a consumer signed an exclusive contract), and such a contract is offered only if this is greater than the profit which Firm 1 could earn by offering no contract at all, i.e. $2 \pi_{1}$. 


\subsection{Exclusive contracts with discrimination and breach penalties}

We now increase contract complexity by allowing Firm 1 to offer contracts including a breach penalty clause. ${ }^{19}$ The game is changed accordingly, as follows.

Stage 1. Firm 1 may offer each consumer a contract specifying that (i) the consumer commits not to purchase from Firm 2; (ii) a lump-sum transfer from Firm 1 to the consumer; and (iii) a penalty which the consumer must pay to Firm 1 if it breaches the exclusivity requirement. Firm 1 can discriminate across consumers.

Stage 2. Consumers simultaneously decide whether to sign the contracts possibly offered to them in Stage 1.

Stage 3. Observing the outcome of Stage 2, Firm 2 may decide to offer some consumers a lump-sum payment in exchange for these consumers breaching the exclusive contract signed with Firm 1.

Stage 4. Consumers who signed an exclusive contract in Stage 2 and were offered by Firm 2 to breach it in Stage 3 decide whether to accept Firm 2's offer. A consumer breaching an exclusive contract signed in Stage 2 receives

\footnotetext{
${ }^{19}$ Unlike SW, we choose to address the question of breach penalties without modifying the assumptions about the firms' cost structure. This will allow us to assess what exactly the impact of allowing for breach penalty provisions is, leaving everything else unchanged.
} 
the lump-sum payment proposed by Firm 2 in Stage 3, and pays Firm 1 the breach penalty provided for as per the exclusive contract it breaches.

Stage 5. Firm 2 decides which consumers it wants to serve. It cannot decide to serve a consumer who signed an exclusive contract in Stage 2 and did not breach it in Stage 4. Each consumer's welfare level and each firm's profit is then determined according to Firm 2's choices in Stage 5. Lump-sum payments or breach penalties provided in the various contracts are added to or subtracted from firms' profits and consumers' welfare level.

The following result, proved in the appendix, shows that if exclusive contracts can include breach penalty provisions, then Firm 2's exclusion occurs only if the joint surplus of Firm 1, Firm 2, and one consumer, is greater under exclusion than under competition.

Proposition 3 If breach penalties are possible, then inefficient entry deterrence occurs if and only if the joint surplus of both firms and one consumer is greater under exclusion than under no exclusion: (i) if $U_{1}+\mathbf{2} \mathbf{b}_{1}>$ $V+2 \pi_{1}+2 \pi_{2}$, then Firm 2 is excluded in any PCPNE; and (ii) if $U_{1}+2 \boldsymbol{b}_{1}<$ $V+2 \pi_{1}+2 \pi_{2}$, then both firms serve both consumers in any PCPNE.

\section{$\underline{\text { Remarks. }}$}

1. If the assumptions of RRW are made, then allowing for breach penalties has no impact on the likelihood of exclusion. This is because, following the logic of Aghion and Bolton (1987), the role of breach penalties is to induce 
the entrant to transfer part of its rent to the pair comprising the incumbent and one consumer. But in RRW, the entrant has no rent, because both firms earn zero profits under competition. In a more general setting however, firms may earn positive profits under competition. The possibility of introducing breach penalties in exclusive contracts in that case reduces the likelihood of exclusion, without eliminating it. What makes inefficient exclusion still possible is that the condition stated in Proposition 3 only takes into account one consumer (in addition to both firms).

2. The fact that breach penalties make exclusion less likely should come as no surprise, because they facilitate the transfer of an entrant's rent to the incumbent, and thus makes entry deterrence less attractive. This may seem to counter Aghion and Bolton's famous (1987) result that breach penalty provisions may cause inefficient exclusion. But there is in fact no contradiction, because that result is entirely driven by informational asymmetries, which sometimes cause the incumbent to exclude by mistake, having set too high a penalty. In Aghion and Bolton (1987) just like in the present paper, the purpose of exclusive contracts with breach penalty provisions is not to exclude, but rather to be breached and generate a penalty payment. 


\subsection{Exclusive contracts with breach penalties and con- ditional offers}

We now further complexify the institutional setup by considering the possibility for contracts to be conditional on the acceptance of other contracts by other consumers. The previous game is modified as follows. In Stage 3, having observed the outcome of Stage 2, Firm 2 can make the following offers to consumers. To consumers who signed an exclusive contract with Firm 1, it may offer a lump-sum payment in exchange for breaching it. From consumers who did not sign an exclusive contract with Firm 1, it may ask for a lump-sum transfer (from the consumer to itself). Finally, if Firm 2 makes offers to both consumers (counting as an offer also the demand for a lumpsum transfer from a consumer), it may state that a given offer to a consumer is valid only if some other offer is accepted by another consumer in Stage 4 . Then, in Stage 4, consumers who were made offers by Firm 2 in Stage 3 decide whether to take them up or not. If these offers were made conditionally on acceptance by both consumers, and only one of them accepts the offer made by Firm 2, then the acceptance decision is not taken into account. In particular, if a consumer (say, consumer a) signed an exclusive contract in Stage 2, agreed to breach it in Stage 3, but Firm 2's offer to breach it was conditional on consumer $b$ making a lump-sum payment to Firm 2, and this last offer was not taken up, then consumer $a$ remains bound by the exclusive contract signed with Firm 1. 
The following result, proved in the appendix, shows that this contractual environment is rich enough to allow Coasian bargaining to take place, implying that inefficient exclusion cannot occur in a PCPNE.

Proposition 4 Under the above assumptions, inefficient entry deterrence does not occur in a PCPNE.

\section{Foreclosing an already present competitor}

We assume now that both firms are present at the time when contracts can be offered to consumers and that both are on an equal footing as regards the ability to offer contracts. This section assesses whether exclusion may occur in a PCPNE in different contractual environments.

\subsection{Simple exclusive contracts without discrimination}

We assume in this subsection that (i) each firm must offer the same contracts to both consumers, and (ii) only simple exclusive or non-exclusive contracts are allowed. A contract mentions a lump-sum transfer and, possibly, an exclusivity clause. The timing of the game is as follows.

Stage 1. Both firms offer as many contracts as they wish (possibly none) to each consumer. They cannot discriminate across consumers.

Stage 2. Consumers simultaneously decide whether to sign the contracts possibly offered to them in Stage 1. The lump-sum payments corresponding 
to the contracts which end up being signed are made.

Stage 3. Observing the outcome of Stage 2, both firms simultaneously decide which consumers they want to serve. A firm cannot serve a consumer who signed an exclusive contract with the other firm in Stage 2 (assuming such a contract has been offered and accepted). However a firm can serve a consumer with whom it did not sign a contract at the previous stage, and it is obliged to serve consumers with whom it is bound by a contract signed in Stage 2 .

In this setting, as Proposition 5, proved in the appendix, establishes, inefficient exclusion cannot occur in equilibrium. The reason is simple: the prohibition of discrimination implies that when offering contracts, the potentially excluding firm (Firm 1) takes into account the utility level of both consumers. But the fact that both firms make simultaneous offers implies that Firm 2 is able to transfer its profits to consumers (through non-exclusive contracts together with lump-sum payments) in order to deter them from signing exclusive contracts with Firm 1. This ability for Firm 2 to make lump-sum payments to consumers implies that Firm 2's profits are taken into account in the relationship between Firm 1 and consumers. Therefore, all parties are taken into account, and the equilibrium outcome must be efficient.

Proposition 5 Inefficient exclusion cannot occur in a PCPNE. 


\subsection{Simple exclusive contracts with discrimination}

In this subsection, the structure of the game is unchanged and we still assume that only simple exclusive or non-exclusive contracts are allowed, but we relax the no-discrimination rule. As Proposition 6 shows, the possibility to discriminate causes inefficient exclusion to occur in equilibrium for some parameter values. The reason is that, if discrimination is allowed, Firm 1 needs only one consumer to sign an exclusive contract in order to evict Firm 2. The parties whose surplus is taken into account when contracts are offered and taken up are thus Firm 1 (which has the choice whether to offer an exclusive contract) ${ }^{20}$, one consumer (the one to whom a hypothetical exclusive contract is offered), and Firm 2 (which can transfer its expected profits by offering non-exclusive contracts). This leaves out one of the two consumers. Exclusion thus occurs if it maximizes the joint surplus of firms and one consumer - which is possible even if exclusion is socially inefficient.

Proposition 6 Under the assumptions made above, there exists a PCPNE in which no firm is excluded, and there exists no PCPNE in which Firm 1 is excluded. If, and only if $2 \boldsymbol{b}_{1}+U_{1}>2 \pi_{1}+2 \pi_{2}+V$, there also exists a PCPNE in which the inefficient exclusion of Firm 2 occurs.

Corollary. 1. Inefficient eviction of an already present competitor is possible. In particular, in the RRW model, if cost and preference parameters

\footnotetext{
${ }^{20}$ Firm 2 also has the option of offering an exclusive contract, but this cannot be an equilibrium strategy because Firm 1 faces no increasing returns and there are thus no cross-customer externalities regarding the acceptance of exclusive contracts hypothetically offered by Firm 2 .
} 
are such that exclusion occurs when Firm 2 is a potential entrant, it also occurs (in one of the two PCPNE) when Firm 2 is already present and firms can only offer simple exclusive contracts.

2. With simple exclusive contracts, efficient eviction is however less likely than inefficient entry deterrence.

Proof of the corollary. Claim 1 results from the fact that under the assumptions of RRW, $\pi_{1}=\pi_{2}=0$, so that the condition for discrimination to occur in Proposition 6 coincides with that in Proposition 2. Claim 2 results from the assumption that $\pi_{2} \geq 0$.

Proposition 6 provides additional support to the idea that in the presence of increasing returns, exclusive contracts can be used to foreclose consumers by discriminating among them so as to exclude rivals. This strategy may deter entry, as stated in RRW or SW, but it may also cause the inefficient eviction of a rival already present in the market.

\subsection{Exclusive contracts with breach penalties}

We now increase contract complexity by allowing firms to offer contracts including a breach penalty clause. In order to make this possibility meaningful, the time structure of the game is modified as follows:

Stage 1. Both firms offer contracts to each consumer. A contract may be exclusive or non-exclusive. An exclusive contract between Firm $i$ and a 
consumer may include a breach penalty clause specifying (i) a payment to be made to Firm $i$ should the consumer breach the exclusivity requirement while still dealing with Firm $i$; and (ii) a payment to be made to Firm $i$ should the consumer breach the exclusivity requirement by not dealing at all with Firm $i .^{21}$ Discrimination across consumers is allowed.

Stage 2. Consumers simultaneously decide whether to sign the contracts possibly offered to them in Stage 1.

Stage 3. Each firm may offer contracts to consumers who signed in Stage 2 an exclusive contract with the other firm. ${ }^{22}$

Stage 4. Consumers simultaneously decide whether to sign the contracts possibly offered to them in Stage 3, taking into account the obligations imposed upon them by the contracts signed in Stage 2 .

Stage 5. Observing the outcome of Stages 2 and 4, both firms simultaneously decide which consumers they want to serve. A firm is obliged to serve a consumer who signed (and did not breach) a contract it proposed, and it cannot serve a consumer who signed an exclusive contract with the other

\footnotetext{
${ }^{21}$ For the sake of tractability, we do not allow for breach penalties in non-exclusive contracts, i.e. for clauses stating that a consumer must compensate a firm for deciding not to deal with it (for example by signing an exclusive contract with a competitor) after having signed a non-exclusive contract. Adding this possibility would only complicate the resolution of the game without changing the results.

${ }^{22}$ The assumption that a firm may offer a contract in Stage 3 only to consumers who previously signed an exclusive contract with the other firm is made for tractability. The results would not change under more general assumptions (e.g., if both firms were allowed to offer contracts to both consumers in Stage 3, irrespective of the actions taken in previous stages).
} 
firm in Stage 2 unless this contract has been breached. It is free to serve or not to serve consumers with whom it is not bound by a contract, and who are not bound by an exclusive contract signed with the other firm.

The following Proposition, proved in the appendix, shows that if both firms make offers simultaneously and contracts may include provisions for breach penalties, then exclusion cannot occur in a PCPNE.

Proposition 7 If both firms can offer contracts simultaneously and exclusive contracts can include provisions for breach penalties, then inefficient exclusion cannot occur in a PCPNE. In addition, both firms earn zero profits in any PCPNE.

The reason why both firms earn zero profits if breach penalty provisions are allowed is that these clauses allow Firm $i$ to induce Firm $j$ to transfer its profits to the pair formed by Firm $i$ and any consumer. When both firms can do that, competition results into each firm "forcing" the other one to transfer its entire profits to consumers. As is proved in the appendix, this logic implies that inefficient exclusion cannot occur in equilibrium.

Proposition 7 means that when both firms can simultaneously make offers, the degree of contract complexity needed for inefficient exclusion to be ruled out is less than in the incumbent-entrant case, as there is no need to supplement breach penalty provisions with the possibility of making conditional offers. One can however check that conditional offers are redundant if both firms can offer contracts and breach penalty provisions are possible, 
in that if they were allowed, inefficient exclusion still could not occur in a PCPNE.

\section{Conclusion}

[INSERT TABLE 2]

The main result of the paper is that as soon as too complex contracts are ruled out, exclusive contracts may cause socially inefficient eviction, and not only entry deterrence, even though the former is less likely than the latter.

In terms of real-world applicability, this theory of foreclosure (as well related ones such as in RRW, SW and BW) does not require an outcome as extreme as full exit by the excluded firm. "Exit" should be considered as a continuous variable: rather than fully exiting, a firm may scale down investment (in R\&D, production facilities, or marketing). The analysis is exactly the same as long as the investment variable involves some increasing returns, in the sense that for a given level of investment, the induced increase in demand is reduced if the firm is barred from serving a given set of consumers (for example, a fixed investment allowing a firm to lower its variable costs could fit into this theory). In such a setting, partial consumer foreclosure induces a firm to scale down investment, which reduces the competitive constraint it is able to exert vis-à-vis those consumers who did not sign an exclusive contract - thus enhancing the market power enjoyed by the firm offering exclusive contracts vis-à-vis all consumers. 
While this paper extends the existing theory and shows that anticompetitive exclusive contracts may arise in more general settings than had been established so far, further work is probably required in order to clarify the "complexity metric". In our quest for an institutional setting rich enough to permit Coasian bargaining, we did not proceed according to a predetermined metric over contractual environments. For example, while it seems straightforward to consider that contracts conditional on many variables are more complex than contracts conditional on fewer variables, there is much less clarity as to whether a game with many moves and countermoves is more or less complex, and more or less plausible, than a game with simultaneous moves. In other words, our claim that "simple" contractual environments allow inefficient exclusion to take place, while "rich" contractual environments do not, is not founded on a rigorous theory of what a simple or a rich environment is. Progress towards a complexity metric could pave the way for more general results about how much complexity is required for Coasian bargaining to take place, both in the "incumbent-entrant" case and in the "two-incumbent" case. 


\section{Table 2. Summary of the results}

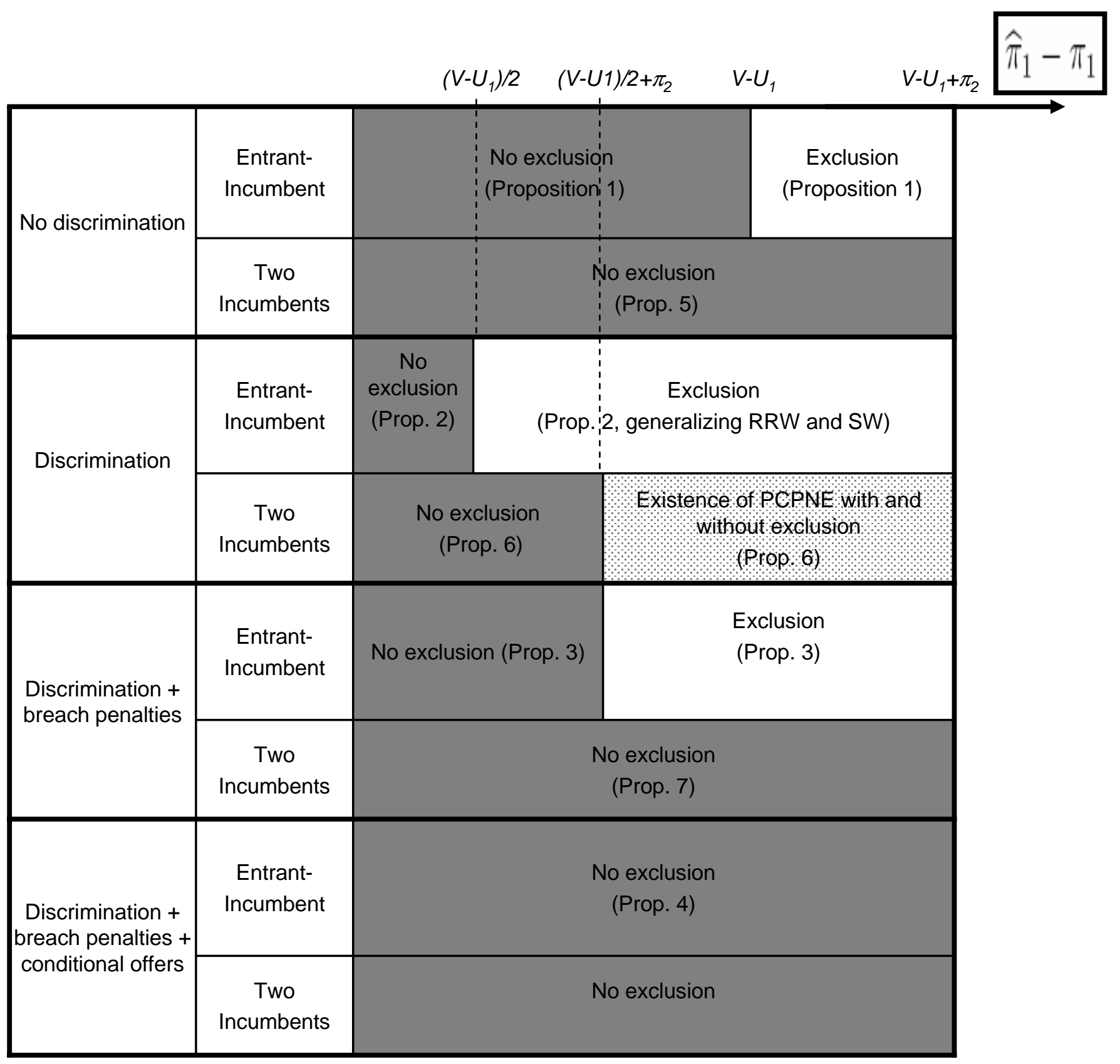




\section{REFERENCES}

Aghion, Philippe, and Patrick Bolton. 1987 "Contracts as a Barrier to Entry." American Economic Review, 77(3): 388-401.

Bernheim, B. Douglas, Bezalel Peleg, and Michael Whinston. 1987. "Coalition-Proof Nash Equilibria. I. Concepts." Journal of Economic Theory, 42(1): 1-12.

Bernheim, B. Douglas, and Michael Whinston. 1998. "Exclusive Dealing.", Journal of Political Economy, 106(1): 64-103.

Bork, Robert. The Antitrust Paradox, New York: Basic Books, 1978.

Carlton, Dennis. 2001. "A General Analysis of Exclusionary Conduct and Refusal to Deal - Why Aspen and Kodak are Misguided." Antitrust Law Journal, 68(3): 659-683.

Comanor, William, and Harry Frech. 1985. "The Competitive Effect of Vertical Agreements: Comment", American Economic Review, 77(5): 1057-1062.

Fumagalli, Chiara, and Massimo Motta. 2006."Exclusive dealing and entry, when buyers compete", American Economic Review, 96(3): 785795 . 
Gans, Joshua, and Stepehn King. 2002. "Exclusionary Contracts and competition for large buyers", International Journal of Industrial Organization, 20: 1363-1381.

Gilbert, Richard. 2000. "Exclusive Dealing, Preferential Dealing, and Dynamic Efficiency," Review of Industrial Organization, 16(2): 167-184.

Hart, Oliver, and Jean Tirole. 1990. "Vertical Integration and Market Foreclosure", Brookings Papers on Economic Activity (Microeconomics), 205286.

Innes, Robert, and Richard Sexton. 1994. "Strategic Buyers and Exclusionary Contracts", American Economic Review, 84(3): 566-584.

Krattenmaker, Thomas, and Steven Salop. 1986. "Competition and Cooperation in the Market for Exclusionary Rights", American Economic Review, Papers and Proceedings of the Ninety-Eighth Annual Meeting of the American Economic Association, 76(2): 109-113.

Lin, Y. Joseph. 1990. "The Dampening-of-Competition Effect of Exclusive Dealing," Journal of Industrial Economics, 39(2): 209-223.

Marvel, Howard P. 1982. "Exclusive Dealing", Journal of Law and Economics, 25: 1-25.

Mathewson, Frank and Ralph Winter. 1987. "The Competitive Effect of Vertical Agreements: Comment." American Economic Review, 77(5): 1057-1062. 
Neeman, Zvika. 1999. "The freedom to contract and the free-rider problem." Journal of Law, Economics and Organizations, 15(3): 685-703.

O'Brien, Daniel, and Greg Shaffer. 1993. "On the Dampening-ofCompetition Effect of Exclusive Dealing." Journal of Industrial Economics, 41(2): $215-221$.

O’Brien, Daniel, and Greg Shaffer. 1997. "Nonlinear supply Contracts, Exclusive Dealing, and Equilibrium Market Foreclosure." Journal of Economics and Management Strategy, 6(4): 755-785.

Ordover, Janusz, Garth Saloner, and Steven Salop. 1990. "Equilibrium Vertical Foreclosure." American Economic Review, 80(1): 127-142.

Posner, Richard. 1976. Antitrust Law: An Economic Perspective. Chicago: University of Chicago Press.

Rasmusen, Eric, J. Mark Ramseyer, and John Shepard Wiley. 1991. "Naked Exclusion." American Economic Review, 81(5): 1137-1145.

Rasmusen, Eric, J. Mark Ramseyer, and John Shepard Wiley. 2004. "Naked Exclusion: Theory and Law."

http://rasmusen.org/pacioli/unpublished/99exrep.txt.

Segal, Ilya. 1999. "Contracting with Externalities." Quarterly Journal of Economics, 114(2): 337-388. 
Segal, Ilya. 2003. "Coordination and Discrimination in Contracting with Externalities: Divide and Conquer?" Journal of Economic Theory, 113(2): 147-181.

Segal, Ilya, and Michael Whinston. 2000a. "Naked Exclusion: Comment." American Economic Review, 90(1): 296-309.

Segal, Ilya, and Michael Whinston. 2000b. "Exclusive Contracts and the Protection of Investments." Rand Journal of Economics, 31 (4): 603-633.

Segal, Ilya, and Michael Whinston. 2003. "Robust Predictions for Bilateral Contracting with Externalities." Econometrica, 71(3): 757-791.

Simpson, John, and Abraham L. Wickelgren. 2005. "Exclusive dealing and entry, when buyers compete: comment."

http://www.eco.utexas.edu/facstaff/Wickelgren/FMcomment-4.pdf

Simpson, J. and A. Wickelgren. 2004. "Naked Exclusion, Efficient Breach, and Downstream Competition."

http://www.cramton.umd.edu/workshop/papers/wickelgren-simpson-nakedexclusion-and-efficient-breach.pdf

Spector, D. 2007. "Adverse Selection and Exclusive Supply Contracts." Unpublished.

Whinston, Michael. 2001. "Exclusivity and Tying in U.S. v Microsoft: What We Know, and Don't Know", Journal of Economic Perspectives, 15 (2): $63-80$. 
Wiley, John. 1998. "Exclusionary Agreements", in The New Palgrave Dictionary of Economics and the Law, ed. Peter Newman, 110-116. Vol. 2. London: MacMillan. 


\section{Appendix}

\section{Proof of Proposition 1}

Consider a hypothetical equilibrium in which exclusion occurs, and let $V^{*}$ denote each consumer's utility level in this hypothetical equilibrium (the no-discrimination clause implies that in equilibrium both consumers enjoy the same utility level). It must be the case that $V^{*} \geq V$. Assume indeed that this is not the case and that $V^{*}<V$. In this case, there necessarily exists an equilibrium in which no consumer accepts the exclusive contract offered by Firm 1 and both consumers enjoy a utility level of $V$. Indeed, if consumer $a$ rejects the contract, then consumer $b$ 's utility from rejecting it as well is $V$ (since rejection by both induces Firm 2 to enter and allows each consumer to be served by both firms). If consumer $a$ takes up the contract, then he will be served by Firm 1 alone and be paid the lump-sum transfer provided for in the exclusive contract offered by Firm 1. He will get the utility level $V^{*}$. If $V^{*}<V$, rejection by both consumers is thus a Pareto-superior equilibrium of the continuation game than acceptance. This implies that in any PCPNE involving exclusion, $V^{*} \geq V$. Since the joint surplus of Firm 1 and consumers is $2\left(\wp_{1}+U_{1}\right)$, Firm 1's profit is at most equal to $2\left(\wp_{1}+U_{1}-V\right)$. For exclusion to be an equilibrium outcome, it must then be the case that $2\left(\wp_{1}+U_{1}-V\right) \geq 2 \pi_{1}$, or equivalently $\wp_{1}+U_{1} \geq \pi_{1}+V$ Otherwise, Firm 1 could increase its profit to $2 \pi_{1}$ by offering no contract at all.

We show now that the converse is true: if $\wp_{1}+U_{1}>\pi_{1}+V$, then exclusion 
must occur in equilibrium. Under no exclusion, Firm 1's profit is $\pi_{1}$. But Firm 1 could earn greater profits by offering the following contract: offer each consumer an exclusive contract against a lump-sum transfer equal to $V-U_{1}+\varepsilon$, with $\varepsilon>0$. Clearly, accepting such a contract increases each consumer's utility level by $\varepsilon$ (if acceptance is pivotal in deterring Firm 2's entry) or by $V-U_{1}+\varepsilon$ (if acceptance is not pivotal). Accepting this contract is thus a dominant strategy, and this contract is accepted by both consumers in equilibrium. Firm 1's profit is equal to $\wp_{1}-\left(V-U_{1}\right)-\varepsilon$, which is strictly greater than $\pi_{1}$ if $\varepsilon$ is small enough. Offering an exclusive contract which will be accepted by consumers is thus a dominant strategy for Firm 1. QED.

\section{Proof of Proposition 2}

First step: if $U_{1}+2 b_{1}>V+2 \pi_{1}$, then exclusion occurs in all PCPNE. We assume that $U_{1}+2 \boldsymbol{b}_{1}>V+2 \pi_{1}$. In a hypothetical no-exclusion equilibrium, Firm 1's profit would be $2 \pi_{1}$. Now consider the following strategy for Firm 1: offer consumer $a$ an exclusive contract against a payment equal to $V-U_{1}+\varepsilon$, where $\varepsilon$ is strictly positive and small, and no contract to consumer $b$. If consumer $a$ accepts this offer, Firm 2 is deterred from entering and consumer $a$ 's surplus is thus $U_{1}+\left(V-U_{1}+\varepsilon\right)=V+\varepsilon$, which is greater than the utility level $V$ it would earn if it rejected the offer, triggering Firm 2's entry. But then, Firm 1's profit will be $2 \mathbf{b}_{1}-\left(V-U_{1}+\varepsilon\right)$, which is strictly greater than $2 \pi_{1}$ if $\varepsilon$ is small enough. Therefore, offering an exclusive contract which is taken up by consumer $a$ allows Firm 1 to increase its profit with respect to a 
hypothetical equilibrium in which Firm 2 is not excluded. This implies that exclusion occurs in equilibrium. More precisely, one can check that the only PCPNE of this game is such that Firm 1 offers one consumer an exclusive contract against a payment equal to $V-U_{1}$, which that consumer accepts, thus deterring Firm 2 from entering.

Second step: if $U_{1}+2 \boldsymbol{b}_{1}<V+2 \pi_{1}$, then exclusion does not occur in any PCPNE. We assume that $U_{1}+2 \boldsymbol{b}_{1}<V+2 \pi_{1}$. By offering no exclusive contract, Firm 1 can obtain a profit equal to $2 \pi_{1}$. We consider now a hypothetical PCPNE involving Firm 2's exclusion. First, we claim that in any such PCPNE, at least one consumer's utility level is no smaller than $V$, and that each consumer's utility level is above $U_{1}$. By signing no contract at all, any consumer is certain to be served at least by Firm 1, which yields a surplus equal to $U_{1}$. This implies that each consumer's surplus is greater than or equal to $U_{1}$. Then, assume that both consumers' equilibrium utility levels are below $V$. This means that each exclusive contract taken up in equilibrium involves a lump-sum payment strictly smaller than $V-U_{1}$. But this implies the existence of an equilibrium of the subgame starting in Period 2 (when consumers decide whether they will sign contracts) in which no consumer signs a contract, yielding each consumer a utility level of $V$ (because Firm 2 enters if no consumer signs an exclusive contract with Firm 1). This equilibrium of the continuation subgame starting in Period 2 yields both consumers a strictly greater utility than the hypothetical equilibrium, which is therefore not a PCPNE. Second, the fact that in any PCPNE involving exclusion, one con- 
sumer's utility level is greater than or equal to $V$, while the other consumer's utility level is greater than or equal to $U_{1}$ implies that in such an equilibrium, Firm 1's profit is no greater than $2\left(U_{1}+b_{1}\right)-V-U_{1}$, which is smaller than $2 \pi_{1}$ by assumption. Therefore, Firm 1 could increase its profit by offering no contract at all and earning $2 \pi_{1}$, so that exclusion does not occur in a PCPNE. QED.

Proof of Proposition 3. First, notice that in any equilibrium with exclusion, each consumer gets a utility level of at least $U_{1}$ and at least one of them gets a utility level greater than or equal to $V$ (the proof of this claim is the same as in the proof of Proposition 2). This implies that the maximum profit which Firm 1 can earn by excluding Firm 2 is $2 \mathbf{b}_{1}-\left(V-U_{1}\right)$. We now show that the maximum profit which Firm 1 can earn in an equilibrium in which Firm 2 is not excluded is equal to $2 \pi_{1}+2 \pi_{2}$. In a no-exclusion equilibrium, no consumer signs a contract, so that each consumer's utility level is equal to $V$. Since Firm 2's equilibrium profit must be nonnegative (otherwise it could do better by deciding to serve no consumer), this implies that Firm 1's profit is smaller than or equal to $2 \pi_{1}+2 \pi_{2}$. What remains to be shown is that Firm 1 can offer a contract such that the only PCPNE of the continuation game yields it a profit arbitrarily close to $2 \pi_{1}+2 \pi_{2}$ while inducing no exclusion. Consider the following strategy: Firm 1 offers consumer $a$ an exclusive contract, together with a lump-sum payment of $V-U_{1}$ and a breach penalty equal to $2 \pi_{2}+V-U_{1}-\varepsilon$ (with $\varepsilon$ very small). If consumer $a$ accepts such a contract, Firm 2 will be ready to offer him 
to breach it against a payment comprised between $2 \pi_{2}-\varepsilon$ and $2 \pi_{2}$, and consumer $a$ will be better off accepting such an offer. His utility will then be greater than $V+\left(V-U_{1}\right)-\left(2 \pi_{2}+V-U_{1}-\varepsilon\right)+\left(2 \pi_{2}-\varepsilon\right)=V$, so that consumer $a$ is better off accepting Firm 1's offer than rejecting it. This proves that Firm 1 can offer a contract inducing Firm 2 to enter, and yielding itself a profit arbitrarily close to $2 \pi_{1}+2 \pi_{2}$. As a consequence, if $2 \pi_{1}+2 \pi_{2}>2 \varpi_{1}-\left(V-U_{1}\right)$, then Firm 1's optimal strategy is to offer an exclusive contract together with a breach penalty clause which will induce Firm 2 to enter. In this case, one can easily check that the only PCPNE is such that Firm 1 offers consumer $a$ (or $b$ ) an exclusive contract together with a lump-sum payment of $V-U_{1}$ and a breach penalty equal to $2 \pi_{2}+V-U_{1}$. Firm 2 then enters and offers this consumer to breach the exclusive contract against a payment of $2 \pi_{2}$. Conversely, if $2 \pi_{1}+2 \pi_{2}<2 \boldsymbol{b}_{1}-\left(V-U_{1}\right)$, then Firm 1's optimal strategy is to offer an exclusive contract with no provision for breach (or with prohibitively high breach penalties). QED.

Proof of Proposition 4. Consider the following offer by Firm 1 in Stage 1: Firm 1 offers consumer $a$ an exclusive contract together with a lump-sum payment of $V-U_{1}+\varepsilon$ and a breach penalty equal to $2 \pi_{2}+2\left(V-U_{1}\right)-\varepsilon$ (with $\varepsilon$ very small). Consumer $a$ obviously takes up this contract in Stage 2, since it guarantees him a utility level equal to at least $V+\varepsilon$ (in case he decides not to breach it). Then, consider Stage 3. Firm 2 cannot induce consumer $a$ to breach the contract by making an unconditional offer. Indeed, Firm 2 is willing to give up at most the entirety of its foreseeable profit, or $2 \pi_{2}$. But 
if consumer $a$ breaches the exclusive contract against a payment of $2 \pi_{2}$, this results into (i) a gain of $V-U_{1}$ due to the shift from being served by Firm 1 alone to being served by both firms, (ii) a gain of $2 \pi_{2}$ (Firm 2's bribe for breaching the contract), and (iii) the breach penalty $2 \pi_{2}+2\left(V-U_{1}\right)-\varepsilon$, leading to a loss of $\left(V-U_{1}\right)-\varepsilon$. Firm 2 can induce consumer $a$ to breach the exclusive contract by simultaneously (i) offering consumer $a$ to breach the contract against a payment $2 \pi_{2}+\left(V-U_{1}\right)-\eta$ (with $0<\eta<\varepsilon$ ); (ii) requiring consumer $b$ to pay $V-U_{1}-\varepsilon^{\prime}$ with $\varepsilon^{\prime}<\eta$; and (iii) stating that the offer to consumer $a$ is conditional on consumer $b$ accepting to make this payment. Clearly, in any PCPNE of the continuation game starting in Stage 4, both consumers decide to accept these offers. Consumer $a$ risks nothing: if consumer $b$ does not accept, then accepting has no consequence for consumer $a$, who remains bound by his exclusive contract with Firm 1. On the other hand, if consumer $b$ accepts, consumer $a$ ends up with a utility level equal to $V+\varepsilon+(\varepsilon-\eta)$, which is greater than the level $V+\varepsilon$ which it would achieve if it did not accept Firm 2's offer. Regarding consumer b's incentive to accept Firm 2's requirement for a payment of $V-U_{1}-\varepsilon^{\prime}$, notice that if consumer $a$ takes up Firm 2's conditional offer, then (i) if consumer $b$ rejects Firm 2 's requirement, consumer $a$ will remain bound by the exclusive contract signed with Firm 1 (by virtue of the conditional nature of Firm 2's offer), so that Firm 2 will decide to serve no consumer in Stage 6, and consumer $b$ will be subjected to Firm 1's monopoly power and have a utility level equal to $U_{1}$. On the other hand, if consumer $b$ accepts Firm 2's requirement, 
consumer $a$ will be released from the exclusive contract signed with Firm 1, Firm 2 will thus decide to serve both consumers, and consumer $b$ will enjoy a utility level equal to $V-\left(V-U_{1}-\varepsilon^{\prime}\right)=U_{1}+\varepsilon^{\prime}$. Thus, both consumers have an interest in accepting Firm 2's offer, inducing Firm 2 to serve both consumers. Firm 2's profit is in turn equal to the profit it would normally earn when serving both consumers, minus its "bribe" to release consumer $a$ from his exclusive contract, plus the payment made by consumer $b$, i.e. $2 \pi_{2}-\left[2 \pi_{2}+\left(V-U_{1}\right)-\eta\right]+\left[V-U_{1}-\varepsilon^{\prime}\right]=\eta-\varepsilon^{\prime}>0$. Thus, faced with the aforementioned contract offered by Firm 1 in Stage 1, consumer $a$ has an incentive to take it up, and Firm 2 can make a positive profit by offering to bribe consumer $a$ into breaching the exclusive contract conditionally on consumer $b$ making a payment to Firm 2. Therefore, in any PCPNE of the continuation game starting in Stage 2, the breach penalty is paid to Firm 1 , which thus earns its "duopoly profit" $2 \pi_{1}$ minus the lump-sum transfer $\left(V-U_{1}+\varepsilon\right)$ paid to consumer $a$ upon signing the exclusive contract, plus the breach penalty $2 \pi_{2}+2\left(V-U_{1}\right)-\varepsilon$, or in total $2 \pi_{1}+2 \pi_{2}+\left(V-U_{1}\right)-2 \varepsilon$. Therefore, Firm 1 can earn a profit arbitrarily close to $\left[2 \pi_{1}+2 \pi_{2}+\left(V-U_{1}\right)\right]$ while inducing Firm 2 to serve both consumers.

In contrast, the maximum profit which Firm 1 can earn while excluding Firm 2 is $2 b_{1}+U_{1}-V$, because in any equilibrium with exclusion, each consumer gets a utility level of at least $U_{1}$ and at least one of them gets a utility level greater than or equal to $V$ (the proof of this claim is the same as in the proof of Proposition 2). Assumption (3), stating that exclusion is socially 
inefficient, is equivalent to $2 \pi_{1}+2 \pi_{2}+\left(V-U_{1}\right)>2 \varpi_{1}+V-U_{1}$, implying that Firm 1's profit-maximizing strategy in Stage 1 involves offering a contract such as the one described above, leading to no exclusion. Therefore, no PCPNE involves exclusion in equilibrium. Finally, one can easily check that the strategies described above, with $\eta=\varepsilon=\varepsilon^{\prime}=0$, define a PCPNE. QED.

\section{Proof of Proposition 5.}

Step 1. There exists a subgame perfect equilibrium such that (i) the equilibrium of the continuation subgame starting in period 2 is coalition-proof, (ii) Firm $i$ (for $i=1$ and $i=2$ ) offers both consumers an exclusive contract with a lump-sum transfer $t_{e i}=\wp_{i}-\pi_{i}+\operatorname{Max}\left[0,\left(\wp_{j}+U_{j}\right)-\left(\pi_{j}+V\right)\right]$ and a non-exclusive contract with a lump-sum transfer of $t_{n i}=\operatorname{Max}\left[0,\left(\wp_{j}+U_{j}\right)-\right.$ $\left.\left(\pi_{j}+V\right)\right]$ (with the notation $\{i ; j\}=\{1 ; 2\}$ ); and (iii) consumers choose to accept both firms' non-exclusive offers.

Proof. First, these transfers are such that each consumer is better off accepting both non-exclusive offers (which yields a payoff $V+t_{n 1}+t_{n 2}$ ) than accepting Firm $i$ 's exclusive offer (which yields a payoff $U_{i}+t_{e i}$ ), while being indifferent between these two options if $t_{n j}>0$. Accepting both firms' non-exclusive offers is thus a weakly dominant strategy and thus defines a PCPNE of the continuation game. Second, consider firms' actions in period 1. If the contracts offered by Firm $j$ are as described above, the cheapest way for Firm $i$ to induce a consumer to be served by both firms in equilibrium involves offering a non-exclusive contract with the smallest positive lump- 
sum transfer required to make the consumer indifferent between accepting both firms' non-exclusive contracts and accepting Firm $j$ 's exclusive contract. This minimal lump-sum transfer is equal to $\operatorname{Max}\left[0 ; U_{j}+t_{e j}-V-t_{n j}\right]=$ $\operatorname{Max}\left[0,\left(\varpi_{j}+U_{j}\right)-\left(\pi_{j}+V\right)\right]=t_{n i}$. Similarly, the cheapest way for Firm $i$ to induce a consumer to purchase from Firm $i$ only in equilibrium involves offering an exclusive contract with the smallest positive lump-sum transfer required to make the consumer indifferent between accepting Firm $i$ 's exclusive contract, and either of the two contracts offered by Firm $j$. This minimal lump-sum transfer is equal to $\operatorname{Max}\left[0 ; U_{j}+t_{e j}-U_{i} ; V+t_{n j}-U_{i}\right]=$ $\operatorname{Max}\left[0 ; \wp_{j}-\pi_{j}+\operatorname{Max}\left[0,\left(\wp_{i}+U_{i}\right)-\left(\pi_{i}+V\right)\right] ;\left(\wp_{j}+U_{j}\right)-\left(\pi_{j}+V\right)\right] \geq t_{e i}$. But, since $\mathfrak{b}_{i}-t_{e i}=\pi_{i}-t_{n i}$, Firm $i$ 's maximal profit, given Firm $j$ 's offers, can be obtained by offering a non-exclusive contract with a lump-sum payment equal to $t_{n i}$. Firm $i$ 's best response to Firm $j$ 's actions is thus such that Firm $i$ offers a non-exclusive contract with a lump-sum payment of $t_{n i}$, and an exclusive contract with a lump-sum payment smaller than or equal to $\operatorname{Max}\left[0 ; U_{j}+t_{e j}-U_{i} ; V+t_{n j}-U_{i}\right]$. Offering a non-exclusive contract with a lump-sum payment of $t_{n i}$, and an exclusive contract with a lump-sum payment of $t_{e i}$ is thus a best response to Firm $j$ 's actions. This proves that the actions described above define a subgame-perfect equilibrium. This also proves that there exists a PCPNE involving no exclusion, and that in this PCPNE, Firm $i$ 's profit is greater than or equal to $2\left(\operatorname{Min}\left[\pi_{i},\left(\pi_{1}+\pi_{2}+V\right)-\left(\wp_{j}+U_{j}\right)\right]\right)$. Indeed, in any hypothetical exclusionary subgame perfect equilibrium, one of the firms earns zero, and is thus 
worse off than in the non-exclusionary equilibrium described above, which implies that there exists at least one non-exclusionary PCPNE.

Step 2. We show that the equilibrium described above is a PCPNE.

Proof. This is equivalent to showing that there exists no subgame-perfect equilibrium such that the continuation subgame starting in period 2 is a PCPNE, and such that (i) each consumer is served by both firms and (ii) for one firm at least, say firm $i$, the equilibrium profit is strictly greater than $2\left(\operatorname{Min}\left[\pi_{i},\left(\pi_{1}+\pi_{2}+V\right)-\left(\wp_{j}+U_{j}\right)\right]\right)$. Assume first that $\left(\wp_{j}+U_{j}\right) \leq$ $\left(\pi_{j}+V\right)$ and that Firm $i$ 's equilibrium profit is greater than $2 \pi_{i}$. This means that one of the consumers signs a non-exclusive contract with Firm $i$ involving a strictly positive payment to Firm $i$, which is impossible since this strategy would be dominated by not signing any contract with Firm $i$. Assume now that $\left(\wp_{j}+U_{j}\right)>\left(\pi_{j}+V\right)$ and that Firm $i$ 's equilibrium profit is strictly greater than $2\left[\left(\pi_{1}+\pi_{2}+V\right)-\left(\wp_{j}+U_{j}\right)\right]$. This means that at least one consumer receives a lump-sum payment from Firm 1 which is strictly lower than $\left(\wp_{j}+U_{j}\right)-\left(\pi_{j}+V\right)$. But if this is the case, then faced with Firm $i$ 's equilibrium non-exclusive offer and a hypothetical exclusive offer proposed by Firm $j$ together with a lump-sum transfer equal to $\emptyset_{j}-\pi_{j}-\varepsilon$ for small enough $\varepsilon$, this consumer would choose the latter. This implies that, by offering such an exclusive contract, Firm $j$ could increase its profit by at least $\varepsilon$ (the reason for this is that in equilibrium the non-exclusive contracts picked by consumers necessarily involve nonnegative transfers from firms to 
consumers). This contradicts the assumption that both consumers are served by both firms in equilibrium.

Step 3. We assume now that there exists a PCPNE in which one of the consumers (at least) is served by only one firm. Let $t_{e i}$ and $t_{n i}$ denote respectively Firm $i$ 's lump-sum transfer associated with the best (from the consumers' viewpoint) exclusive and a non-exclusive contract it offers (offering no contract can be interpreted as offering a transfer equal to minus infinity, which will be rejected by consumers in any subgame perfect equilibrium of the continuation game). Assume that consumer $a$ is served by one firm only, say Firm $i$. Since both consumers are offered the same contracts, they both get the same utility level $U^{*}$. But $U^{*} \geq \operatorname{Max}\left(V+\pi_{j}, U_{j}+\wp_{j}\right)$, because otherwise Firm $j$ would have an interest in offering to each consumer it does not serve in the hypothetical equilibrium a non-exclusive contract together with a lump-sum payment equal to $\pi_{j}-\varepsilon$, as well as an exclusive contract together with a lump-sum payment equal to $\wp_{j}-\varepsilon$, with $\varepsilon>0$ being very small. Such a contract would be picked by any consumer being offered it (because it would yield a payoff greater than $U^{*}$ ), and this would increase Firm $j$ 's profit. Since both consumers are offered the same contracts, Firm $i$ 's profit is the same as the one it would earn if both consumers were picking an exclusive contract it offers (otherwise, this means that Firm $i$ could increase its profit by offering only an exclusive contract to both consumers, or only a non-exclusive contract to both consumers). Firm $i$ 's equilibrium profit is thus equal to $2\left(\wp_{i}+U_{i}-U^{*}\right) \leq 2 \operatorname{Min}\left(\wp_{i}+U_{i}-V-\pi_{j}, \wp_{i}+U_{i}-U_{j}-\wp_{j}\right) \leq$ 
$2 \operatorname{Min}\left(\pi_{i},\left(\pi_{1}+\pi_{2}+V\right)-\left(\wp_{j}+U_{j}\right)\right)$, which is smaller than or equal to Firm $i$ 's profit in some non-exclusionary PCPNE, as shown in Step 1. This implies that the hypothetical exclusive PCPNE is Pareto-dominated, from the point of view of firms, by some non-exclusive PCPNE. This implies that all PCPNE are non-exclusive.

\section{Proof of Proposition 6.}

First, it can easily be checked that the PCPNE described in Step 1 of the proof of Proposition 5 is still a PCPNE when discriminatory offers are allowed.

Second, we show that in any PCPNE, Firm 1 serves both consumers. Assume that there exists an equilibrium in which one consumer at least, say consumer $a$, is not served by Firm 1 . This means that in equilibrium consumer $a$ signs an exclusive contract with Firm 2, against some lump-sum payment $t_{e 2}$. But the inequality $U_{2}+t_{e 2}^{a} \geq \operatorname{Max}\left[\wp_{1}+U_{1} ; \pi_{1}+V\right]$ must hold, because otherwise Firm 1 could increase its profit by offering consumer $a$ an exclusive contract against a lump-sum transfer equal to $U_{2}+t_{e 2}^{a}-U_{1}+\varepsilon$ and a non-exclusive contract against a lump-sum transfer equal to $U_{2}+t_{e 2}^{a}-V+\varepsilon$, which would be chosen by consumer $a$ while yielding Firm 1 a strictly positive profit if $\varepsilon$ is small enough. In equilibrium, Firm 2 necessarily serves consumer $b$ (this is because Firm 2 loses money when serving one consumer only, so that if it serves consumer $a$ it must also serve consumer $b$ ). Let us define $\pi_{2 b}=\pi_{2}-t_{b}^{2}$ if in equilibrium consumer $b$ is served by both firms and Firm 2 
pays consumer $b$ a lump-sum transfer $t_{b}^{2}$, and $\pi_{2 b}=\wp_{2}-t_{b}^{2}$ if in equilibrium consumer $b$ is served by Firm 2 only and Firm 2 pays consumer $b$ a lump-sum transfer $t_{b}^{2}$. The inequality $U_{2}+t_{e 2}^{a} \geq \operatorname{Max}\left[\varpi_{1}+U_{1} ; \pi_{1}+V\right]$ implies that Firm 2 's equilibrium profit is smaller than $\pi_{2 b}+\wp_{2}+U_{2}-\operatorname{Max}\left[\wp_{1}+U_{1} ; \pi_{1}+V\right]$. But, as proved above, there also exists an equilibrium which is a PCPNE of the subgame starting in Period 2, such that in period 1 Firm $i$ (for $i=1$ and $i=2$ ) offers consumer $a$ an exclusive contract with a lump-sum transfer $t_{e i}^{\prime}=\wp_{i}-\pi_{i}+\operatorname{Max}\left[0,\left(\mathfrak{b}_{j}+U_{j}\right)-\left(\pi_{j}+V\right)\right]$ and a non-exclusive contract with a lump-sum transfer of $t_{n i}^{\prime}=\operatorname{Max}\left[0,\left(\wp_{j}+U_{j}\right)-\left(\pi_{j}+V\right)\right]$ (with the notation $\{i ; j\}=\{1 ; 2\})$; and (iii) consumer $a$ chooses to accept both firms' nonexclusive offers. If both firms changed their offers to consumer $a$ accordingly (while leaving unchanged their offers to consumer $b$ ), the outcome would still be an equilibrium, Firm 1's profit would increase by $\operatorname{Min}\left[\pi_{1},\left(\pi_{1}+\pi_{2}+V\right)-\right.$ $\left.\left(\wp_{2}+U_{2}\right)\right]$ and Firm 2's profit would increase by at least $\left(\pi_{1}+\pi_{2}+V\right)-\left(\wp_{2}+\right.$ $U_{2}$ ). This means that the equilibrium originally considered is not a PCPNE.

Third, in order to prove that there exists a PCPNE in which Firm 2 is excluded if and only if $2 \boldsymbol{\varpi}_{1}+U_{1}>2 \pi_{1}+2 \pi_{2}+V$, we distinguish two cases. First case: $\pi_{2}+V>\boldsymbol{b}_{2}+U_{2}$. Step 1. Assume that $2 \boldsymbol{b}_{1}+U_{1}>2 \pi_{1}+$ $2 \pi_{2}+V$. We show that there exists an equilibrium in which Firm 1 offers consumer $a$ an exclusive contract together with a lump-sum payment equal to $2 \pi_{2}+V-U_{1}$, Firm 2 offers consumer $a$ a non-exclusive contract together with a lump-sum payment equal to $2 \pi_{2}$, and consumer $a$ chooses to accept Firm 1's exclusive contract. Clearly, consumer $a$ is indifferent between both 
contracts and accepting either makes him better off than accepting none. Firm 1 cannot offer less in an exclusive contract (this would cause consumer $a$ to accept Firm 2's non-exclusive contract and cause Firm 1's profit to fall from $2 \boldsymbol{b}_{1}+U_{1}-2 \pi_{2}-V$ to $2 \pi_{1}$ ), and Firm 2 cannot avoid being excluded (offering a more generous non-exclusive contract would cause losses, and the inequality $\boldsymbol{b}_{2}+U_{2}<\pi_{2}+V$ implies that providing consumer $a$ with a given utility level is more expensive for Firm 2 using an exclusive than a nonexclusive contract). This proves that the aforementioned actions define an equilibrium, which is also a PCPNE of the subgame starting in period 2 (this is because consumer $a$ is the only agent making a decision in period 2). Finally, Firm 1's profit in this equilibrium, at $2 \boldsymbol{b}_{1}+U_{1}-2 \pi_{2}-V$, is greater than its level in the only non-exclusive PCPNE (where it is equal to $2 \pi_{1}$ if $\left.\emptyset_{2}+U_{2}<\pi_{2}+V\right)$. Also, this equilibrium is a PCPNE because Firm 2 would earn zero profit in the out-of-equilibrium event in which consumer $a$ would choose to accept its contract rather than Firm 1's exclusive one.

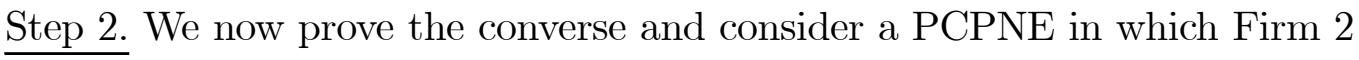
is excluded. Two cases can arise, depending on whether one or two consumers sign an exclusive contract with Firm 1 in equilibrium. If two consumers do, let $t_{e 1}^{k}(k=a, b)$ denote the equilibrium lump-sum transfer paid by Firm 1 to consumer $k$. If $t_{e 1}^{a}+t_{e 1}^{b}<2 \pi_{2}+2 V-2 U_{1}$, then Firm 2 can profitably avoid exclusion by offering consumer $k$ a non-exclusive contract together with a lump-sum transfer equal to $t_{e 1}^{k}-V+U_{1}+\varepsilon$, with $\varepsilon$ small enough. Thus $t_{e 1}^{a}+t_{e 1}^{b} \geq 2 \pi_{2}+2 V-2 U_{1}$, implying that Firm 1's profit is smaller 
than or equal to $2 b_{1}-2 \pi_{2}-2 V+2 U_{1}$, which is strictly smaller than $2 \pi_{1}$ by (3). If only one consumer, say consumer $a$, signs an exclusive contract with Firm 1 in equilibrium, against a lump-sum transfer $t_{e 1}^{a}$, then necessarily $t_{e 1}^{a} \geq 2 \pi_{2}+V-U_{1}$, because otherwise Firm 2 could profitably avoid exclusion by offering consumer $a$ a non-exclusive contract together with a lump-sum transfer equal to $t_{e 1}^{k}-V+U_{1}+\varepsilon$, with $\varepsilon$ small enough. Firm 1's profit is thus smaller than or equal to $2 \boldsymbol{\varpi}_{1}-2 \pi_{2}-V+U_{1}$. The fact that the equilibrium considered is a PCPNE implies that Firm 1's equilibrium profit is strictly greater than Firm 1's profit in the only non-exclusionary PCPNE, i.e. greater than $2 \pi_{1}$, which implies that $2 \boldsymbol{b}_{1}-2 \pi_{2}-V+U_{1}>2 \pi_{1}$, or equivalently $2 \boldsymbol{b}_{1}+U_{1}>2 \pi_{1}+2 \pi_{2}+V$.

Second case: $\emptyset_{2}+U_{2}>\pi_{2}+V$. Step 1 . Assume that $2 \boldsymbol{b}_{1}+U_{1}>2 \pi_{1}+2 \pi_{2}+$ $V$. We show that there exists a PCPNE in which Firm 1 offers consumer $a$ an exclusive contract together with a lump-sum payment equal to $2\left(\boldsymbol{\emptyset}_{2}+\right.$ $\left.U_{2}\right)-\left(V+U_{1}\right)$, Firm 2 offers consumer $a$ an exclusive contract together with a lump-sum payment equal to $2 \boldsymbol{b}_{2}+U_{2}-V$, and in equilibrium consumer $a$ chooses to accept Firm 1's exclusive contract. In order to prove that Firm 2's strategy is a best response, notice that in order to avoid exclusion at lowest possible cost, Firm 2 has to offer consumer $a$ an exclusive contract (this is because the inequality $\omega_{2}+U_{2}>\pi_{2}+V$ implies that exclusion is jointly optimal for the Firm 2 - consumer $a$ pair) together with a transfer yielding consumer $a$ at least the same utility as it would get by accepting Firm 1's offer, i.e., a transfer equal to $\mathbf{2} \boldsymbol{b}_{2}+U_{2}-V$. But in any subgame-perfect 
equilibrium such that consumer $a$ signs a contract with Firm 2, consumer $b$ knows that it can get a utility of at least $V$ simply by signing no contract. Thus, the maximum profit Firm 2 can derive from serving consumer $b$ is $\emptyset_{2}+U_{2}-V$, obtained by offering consumer $b$ an exclusive contract against a transfer of $V-U_{2}$, leaving consumer $b$ with a utility level of at least $V$. Thus, given Firm 1's offer, Firm 2 cannot obtain a profit greater than $2 b_{2}-\left(2 b_{2}+U_{2}-V\right)+U_{2}-V=0$. Firm 2's strategy is thus a best response. Conversely, Firm 1's strategy is a best response to Firm 2's, because the transfer offered to consumer $a$ is the smallest leading consumer $a$ not to choose to accept Firm 2's offer, and Firm 1's ensuing profit is greater than the profit level $\pi_{1}$ which it would earn if it offered no contract at all (or no contract which consumer $a$ would prefer over Firm 2's offer). Finally, in order to prove that these strategies form a PCPNE, it is enough to check that Firm 1 's profit is greater than that it would earn in the only non-exclusive PCPNE, i.e. that $2 \wp_{1}-\left[2\left(\varpi_{2}+U_{2}\right)-\left(V+U_{1}\right)\right]>2 \pi_{1}-2\left[\left(\wp_{2}+U_{2}\right)-\left(\pi_{2}+V\right)\right]$, which is equivalent to the assumed inequality, i.e. $2 \boldsymbol{b}_{1}+U_{1}>2 \pi_{1}+2 \pi_{2}+V$.

Step 2. Conversely, we prove that if Firm 2 is excluded in a PCPNE, then $2 \boldsymbol{b}_{1}+U_{1}>2 \pi_{1}+2 \pi_{2}+V$. Two cases can arise, depending on whether one or two consumers sign an exclusive contract with Firm 1 in equilibrium. If two consumers do, let $t_{e 1}^{k}(k=a, b)$ denote the equilibrium lump-sum transfer paid by Firm 1 to consumer $k$. If $t_{e 1}^{a}+t_{e 1}^{b}<2 b_{2}+2 U_{2}-2 U_{1}$, then Firm 2 can profitably avoid exclusion by offering consumer $k$ an exclusive contract together with a lump-sum transfer equal to $t_{e 1}^{k}-U_{2}+U_{1}+\varepsilon$, with $\varepsilon$ small 
enough. Thus $t_{e 1}^{a}+t_{e 1}^{b} \geq 2 \pi_{2}+2 U_{2}-2 U_{1}$, implying that Firm 1's profit is smaller than or equal to $2\left(\wp_{1}-\wp_{2}-U_{2}+U_{1}\right)$, which is strictly smaller than $2\left[\pi_{1}-\left(\omega_{2}+U_{2}\right)+\left(\pi_{2}+V\right)\right]$ by (3). Since the right-hand side of this inequality is equal to Firm 1's profit in the non-exclusive PCPNE, it follows that there is no exclusive PCPNE in which both consumers sign an exclusive contract. If only one consumer, say consumer $a$, signs an exclusive contract with Firm 1 in equilibrium, against a lump-sum transfer $t_{e 1}^{a}$, then necessarily $t_{e 1}^{a} \geq 2\left(\wp_{2}+U_{2}\right)-\left(V+U_{1}\right)$, because otherwise Firm 2 could profitably avoid exclusion by offering consumer $a$ an exclusive contract together with a lumpsum transfer equal to $t_{e 1}^{k}-U_{2}+U_{1}+\varepsilon$, and consumer $b$ an exclusive contract together with a lump-sum transfer equal to $V-U_{2}+\varepsilon$, with $\varepsilon$ small enough. Firm 1's profit is thus smaller than or equal to $2 b_{1}-\left[2\left(\wp_{2}+U_{2}\right)-\left(V+U_{1}\right)\right]$. The fact that the equilibrium considered is a PCPNE implies that Firm 1's equilibrium profit is strictly greater than Firm 1's profit in the only nonexclusionary PCPNE, i.e. greater than $2 \pi_{1}-2\left[\left(\wp_{2}+U_{2}\right)-\left(\pi_{2}+V\right)\right]$, which implies that $2 \boldsymbol{b}_{1}+U_{1}>2 \pi_{1}+2 \pi_{2}+V$.

\section{Proof of Proposition 7}

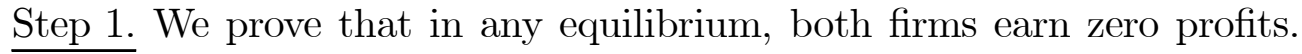
The reason is that if Firm $i$ earned positive profits in a hypothetical equilibrium, the other firm could increase its profit by offering in stage 1 an exclusive contract together with a breach penalty clause having the effect of inducing Firm $i$ to relinquish some of its profit in Stage 3, to its own profit. 


\section{Proof.}

We start by showing that it is impossible in equilibrium for a consumer, say consumer $a$, to make a strictly positive payment to Firm $i$ even though it is not served by Firm $i$. This could happen only if consumer $a$ signed an exclusive contract with Firm $i$ together with a transfer $t$ and a breach penalty $t^{\prime}>t$, before breaching it and paying the penalty . But such an outcome cannot be an equilibrium, because in that case Firm $j$ could profitably deviate in Stage 1 by offering consumer $a$ an exclusive contract (with no breach possibility), together with a transfer $U_{i}+t+\left(t^{\prime}-t\right) / 2$.

Assume now that Firm $i$ earns a strictly positive profit in equilibrium. This means that there exists a consumer, say consumer $a$, such that in equilibrium (with $t$ denoting the transfer from Firm $i$ to consumer $a$ ) either (i) Firm $i$ is the only firm serving consumer $a$, and $t<\boldsymbol{b}_{i}$, or (ii) both firms serve consumer $a$,and $t<\pi_{i}$. Let $U_{a}^{*}$ denote consumer $a$ 's equilibrium surplus level. Firm $j$ could increase its profit by offering consumer $a$, in Stage 1, an exclusive contract together with a transfer of $U_{a}^{*}-U_{j}+\varepsilon$ and a penalty for breach equal to $t+V-U_{j}+2 \varepsilon$ (case (i)), or $t+U_{i}-U_{j}+2 \varepsilon$ (case (ii)), with $\varepsilon>0$ small enough. Such a contract would be accepted by consumer $a$ in Stage 2 (because it would provide consumer $a$ with a surplus greater than in the original equilibrium, by $\varepsilon$, and thus greater than that induced by any other contract offered to consumer $a$ after the abovedescribed deviation). Following this action by Firm $j$, and consumer $a$ 's subsequent acceptance decision, Firm $i$ would be better off making making an offer which consumer 
$a$ wants to accept than not making such an offer, because it could for example increase its profit (relative to the situation in which it would not offer a contract inducing consumer $a$ to breach Firm 2's abovementioned exclusive contract) by offering consumer $a$ in Period 3 a non-exclusive (case (i)) or an exclusive (case (ii)) contract together with a transfer $t+2 \varepsilon$. The payment of the breach penalty by consumer $a$ would increase Firm $j$ 's profit by $\varepsilon$, making Firm $j$ 's deviation from the postulated equilibrium profitable.

Step 2. The following actions always form a PCPNE in which no exclusion takes place. Both firms offer in Stage 1 the same type of contract: Firm $i$ offers each consumer an exclusive contract, together with (i) a transfer $\pi_{i}+\pi_{j}+V-U_{i}$; (ii) a clause specifying a payment for breach equal to $\pi_{j}+V$ $U_{i}(i \neq j)$, owed to Firm $i$ if the consumer, having signed the contract, later decides to drop the exclusivity requirement while still dealing with Firm $i$; and (iii) a clause specifying an infinite payment to Firm $i$ if the consumer later decides not to deal with it. In Stage 2, each consumer signs one of the two such contracts offered to him (being indifferent between both). In Stage 3, if Firm $i$ 's Stage 1 contract was picked by a consumer, then Firm $j$ offers this consumer a non-exclusive contract together with a transfer equal to $\pi_{j}$, which is accepted in Stage 4, causing the breach penalty to be paid to Firm $i$, as per the contract signed in Stage 2 .

Step 3. In any PCPNE, each consumer's equilibrium utility level is at least $\pi_{1}+V$. 
Proof. If for example consumer b's equilibrium utility level $U_{b}^{*}$ were less than $\pi_{1}+V$, Firm 1 could increase its profit by offering no contract at all to consumer $a$, and by offering consumer $b$ a non-exclusive contract together with a transfer strictly between $U_{b}^{*}-V$ and $\pi_{1}$. After such offers by Firm 1 in Stage 1, Firm 2 would serve both consumers in any subgame-perfect equilibrium of the continuation game starting in Stage 2 (whatever its own period 1 offers), because no consumer would be bound to Firm 1 by an exclusivity requirement. This being anticipated by consumer $b$ in Stage 2 implies that consumer $b$, by signing Firm 1's contract, could guarantee itself a utility level strictly greater than $U_{b}^{*}$ (because the transfer $U_{b}^{*}-V$ would be supplemented with at least $V$, a consumer's surplus from dealing with both firms). This implies that in Stage 2, consumer $b$ does not sign any exclusive contract hypothetically offered by Firm 2 in Stage 1 (because any exclusive contract offered by Firm 2 to consumer $b$ in the hypothetical equilibrium yields consumer $b$ a utility level smaller than or equal to $U_{b}^{*}$.) As a consequence, after Firm 1's deviation, Firm 1 deals with at least consumer $b$, which accepts its offer. Firm 1 thus earns a strictly positive profit, because the transfer to consumer $b$ is strictly below $\pi_{1}$. But, since Firm 1's equilibrium profit is zero (as per Step 1), this deviation away from equilibrium would make Firm 1 strictly better off.

Step 4. In any PCPNE, $U_{a}^{*}+U_{b}^{*} \geq 2\left(\pi_{1}+\pi_{2}+V\right)$.

Assume that this were not the case. Then Firm 2 could increase its profit 
by making the following offers in Stage 1: offer each consumer an exclusive contract together with a transfer $U_{c}^{*}-U_{2}+\varepsilon$ (with $c=a$ and $c=b$ ), together with a clause specifying a penalty $\pi_{1}+V-U_{2}-\varepsilon$ for breaching the exclusivity requirement, and an infinite penalty for not dealing with Firm 2 at all. Each consumer would be induced to choose this contract offered by Firm 2. The reason is that, by not doing so, a consumer ends up with a utility level no greater than $U_{c}^{*}$ (it may earn $U_{c}^{*}$ by signing Firm 1's equilibrium offer, or at most $V<U_{c}^{*}$ by signing no contract at all). Firm 1's optimal action in Stage 3 is thus to offer a non-exclusive contract inducing both consumers to breach Firm 2's contract, because this can be done by offering a transfer equal to (for example) $\pi_{1}-\varepsilon / 2$, leaving Firm 1 with a profit $\varepsilon / 2$ per consumer. Firm 2 's profit in any continuation subgame following its deviation away from equilibrium would thus be equal to $2 \pi_{2}+2\left(\pi_{1}+V-U_{2}-\varepsilon\right)-\left(U_{a}^{*}+U_{b}^{*}-\right.$ $\left.2 U_{2}+2 \varepsilon\right)=2\left(\pi_{1}+\pi_{2}+V\right)-\left(U_{a}^{*}+U_{b}^{*}\right)-4 \varepsilon$. Since equilibrium profits are zero this implies that if $U_{a}^{*}+U_{b}^{*}<2\left(\pi_{1}+\pi_{2}+V\right)$, Firm 2 could deviate and earn a strictly positive profit, and thus that $U_{a}^{*}+U_{b}^{*} \geq 2\left(\pi_{1}+\pi_{2}+V\right)$.

Step 5. Assumption (3) implies that total surplus (i.e. the sum of firms' profits and the surplus of both consumers) is maximized when each firm serves both consumers; and that it is then equal to $2\left(\pi_{1}+\pi_{2}+V\right)$. The inequality $U_{a}^{*}+U_{b}^{*} \geq 2\left(\pi_{1}+\pi_{2}+V\right)$, proved in Step 4, implies that if either firm served zero or one consumer, then total surplus would be strictly less than consumer surplus, so that at least one firm's profit would be strictly negative, which is impossible in equilibrium, since each firm can guarantee 
itself at least zero profits by deciding to offer no contracts and not to deal with any consumer. This implies that in any PCPNE, each firm serves both consumers. 